\title{
Sickness absenteeism and associated factors among horticulture employees in lume district, southeast Ethiopia
}

\author{
Sebsibe Tadesse ${ }^{1 *}$, Kamil Ebrahim² ${ }^{2}$ and Zemichael Gizaw ${ }^{1}$
}

\begin{abstract}
Background: Sickness absenteeism is the major occupational health problem in developing countries where the majority of working population are engaged in hazardous sectors, such as agriculture. However, there is a dearth of studies clarifying the situation in most of Subsaharan African countries, like Ethiopia. The present study determined the magnitude of sickness absenteeism and associated factors among horticulture employees in Lume District, southeast Ethiopia.

Methods: An institutional-based cross-sectional study was conducted among horticulture employees in Lume District, southeast Ethiopia from March to May 2014. Stratified sampling followed by simple random sampling techniques was used to select the study participants. A pre-tested and structured questionnaire was used to collect data. Multivariable analyses were employed to see the effect of explanatory variables on dependent variable.

Results: The magnitude of sickness absenteeism was $58.8 \%$ [95 \% Cl: $(54.9,62.5)]$ in the past three months. Absence of periodic medical checkup, working for more than $48 \mathrm{~h}$ per week, working overtime, job dissatisfaction, and job stress were factors significantly associated with sickness absenteeism.

Conclusions: In this study a relatively higher rate of sickness absenteeism was reported compared to other studies. Interventions to reduce sickness absenteeism should focus on areas, such as periodic medical checkup, monitoring work schedules, improving employees' job satisfaction, and managing job stress.
\end{abstract}

Keywords: Employees, Horticulture, Sickness absenteeism, Ethiopia

\section{Background}

Sickness absenteeism is the major occupational health problem in developing countries where the majority of working population are engaged in hazardous sectors, such as agriculture; causing loss of work-hours, reduced productivity and workplace disputes $[1-5]$. According to International Labor Organization 2008, more than 317 million accidents and diseases occurred on the job annually; and about two-thirds of them caused employees away from work for four working days resulting in economic effects and loss of labor time in both developing and developed countries [6]. In Subsaharan Africa, 42 million work-related accidents caused at least three days absence from work in which agriculture plays the major role [2].

\footnotetext{
* Correspondence: sbsbtadesse90@gmail.com

${ }^{1}$ Institute of Public Health, The University of Gondar, Gondar, Ethiopia

Full list of author information is available at the end of the article
}

About half million accidents caused at least four days off work in Ethiopia [7].

Horticulture investment is the most growing agriculture sector in East Africa, especially in the lowland regions of Ethiopia [8]. The industry uses many hazardous chemicals that may affect the health of employees if proper safety procedures are not followed $[2,5]$. However, there is limited evidence on the magnitude, nature and role of different factors associated with sickness absenteeism among horticulture employees in Ethiopia. Moreover, many organizations do not have proper data recording and reporting systems to generate statistics that shows how cosmic the problem is at local and national levels [9]. Therefore, this study aimed to determine the magnitude of sickness absenteeism and associated factors among horticulture employees in Lume District, southeast Ethiopia. The findings of the study 
could provide information for safety officers, employers and policy makers to design strategies that aid to prevent the different health and safety hazards and improve employees' attendance.

\section{Methods}

Study area, design and period

An institutional-based cross-sectional study was conducted to assess the magnitude of sickness absenteeism and associated factors among horticulture employees in Lume District, southeast Ethiopia, from March to May 2014. The district is located at $75 \mathrm{~km}$ East of Addis Ababa, the capital city of Ethiopia. According to the 2007 Ethiopian population statistics, the district has a total of 117,080 populations. Of whom, $51.4 \%$ were males and $33 \%$ were urban dwellers [10]. The study covered eight horticulture industries employing more than $80 \%$ of all employed workers in the district. During the investigation, there are 5900 employees working in the industries; $62.9 \%$ of whom were females [11].

\section{Participants and data collection}

All horticulture employees who have worked for at least three months prior to the study period were included in the study until the required sample size was obtained. Women on maternity leave during the time of data collection were excluded from the study. Data were collected using structured interview questionnaire comprising of workplace stress scale developed by Marlin Company and the American Institute of Stress [12] and generic job satisfaction scale developed by Scott Macdonald and Peter Macintyre [13] with some modification. The questionnaire also contained detailed information on socio-demographic, behavioral and other workplace conditions.

\section{Sample size calculation}

Epi info version 7 was used to determine the sample size required for this study by taking 5900 total population, $50 \%$ expected proportion of sickness absenteeism, $4 \%$ confidence limit, and $95 \%$ confidence level. By adding $10 \%$ non-response rate, the total sample size was 600 .

\section{Sampling procedure}

Stratified sampling followed by simple random sampling techniques was used to select the study participants. That is, the industries were stratified into three departments, namely production, technical and management department. Then, the total of 600 samples was proportionally allocated to each department. The participants were drawn from the factory's list of workers using simple random sampling.

\section{Data quality control}

The training of data collectors and supervisors emphasized issues such as data collection instrument, field methods, inclusion-exclusion criteria, time of interview, and record keeping. The completed questionnaires were spot-checked and reviewed on a daily basis to ensure the completeness and consistency of the data collected. The interview questionnaire was pre-tested on 40 respondents who had characteristics nearly similar to employees in Lume district in order to identify potential problem areas, unanticipated interpretations, and cultural objections to any of the questions. Based on the pre-test results, the questionnaire was adjusted contextually.

\section{Data management and statistical analyses}

Data entered and cleaned using Epi info version 7 statistical software were analyzed on SPSS version 20. Frequency distribution, mean, standard deviation, and percentage, were employed for most variables. All independent variables were fitted separately into bivariate logistic model to evaluate the degree of association with sickness absenteeism. Then, variables with a p-value $<$ 0.20 were exported to multivariable logistic regression model to control confounders. The odds ratio (OR) with a $95 \%$ confidence interval (CI) was used to test the statistical significance of variables.

\section{Operational definitions \\ Horticulture}

Organization that produces fruits, vegetables and flowers and avail on level of local and global market [8].

\section{Sickness absenteeism}

Self-reported employees' absence from their normal duty for the reasons stemming from health problem in the past three months.

\section{Job stress}

The employee was considered as stressed with work when his/her sum of workplace stress scale score was 21 or above [12].

\section{Satisfied with job}

The employee was considered as satisfied with job when his/her sum of generic job satisfaction scale score was 32 or above [13].

\section{Permanent employee}

Any contract of employment between employee and employer concluded for an indefinite period [14].

\section{Temporary employee}

Any employment contract between employee and employer made for definite period [14]. 


\section{Overtime work}

An employee was considered as worked overtime when she/he had worked on average greater than or equal to $2 \mathrm{~h}$ more than the standard working hours per week within the past 3 months [14].

\section{Cigarette smoker}

An employee who was smoking one cigarette a day for at least one year [3].

\section{Alcohol drinker}

An employee who drink at least five drinks per week for men and two drinks per week for women for at least one year [3].

\section{Khat chewer}

An employee chewing Khat three times a week for at least one year [3].

\section{Attendance-based incentive}

An incentive provided for employee for his/her being only present at work.

\section{Ethical considerations}

The study protocol was reviewed and approved by the Institutional Review Board of the University of Gondar via the Institute of Public Health. Permission was obtained from Lume District Labor and Social Affairs Office prior to data collection. Study participants were interviewed after informed written consent was obtained. They were also informed that their participation was voluntary and that they could withdraw from the interview at any time without consequences. The participants were assured that their responses would be treated confidentially through the use of strict coding measures.

\section{Literature search strategy}

PubMed, Medline, and Scopus were the main databases searched for literature and bibliographic alerts were set up for additional papers to be identified whenever they cited key articles. Keywords for the literature search were identified by means of Medical Subject Headings (MeSH) thesaurus which is available through PubMed online (http://www.ncbi.nlm.nih.gov/pubmed). Some MeSH terms used were 'horticulture', 'horticulture employees', 'horticulture workers', 'sickness absenteeism', and 'workplace factors'. Although the bibliographic search was meant to find the most up-to-date information, some old but highly influential papers were also reviewed. EndNote software (http://www.endnote.com/) was used to store citations together with their respective articles in pdf format, so that an annotated bibliography could be built and eventually cited and referenced.

\section{Results}

Socio-demographic characteristics

A total of 590 employees completed the questionnaire making response rate $98.3 \%$. Of whom $71.9 \%$ were females. The mean age with a standard deviation of the employees was 26.9 \pm 7.1 . More than two-thirds, $70.8 \%$, of them belonged to the age group of 19-29 years. Those who attended primary education were $32.9 \%$. More than two-thirds, $70.5 \%$, served for less than five years. Regarding religion $74.9 \%$ of the employees were Christian. The married were $44.6 \%$. Nearly half, $48.3 \%$, had a monthly salary of less than or equal to Birr 700 (Table 1).

\section{Workplace characteristics}

The majority, $89.2 \%$, of the respondents were permanent employees. Regarding hours spent on work $88.6 \%$ of

Table 1 Socio-demographic characteristics of horticulture employees in Lume district, southeast Ethiopia, 2014

\begin{tabular}{|c|c|c|}
\hline Variables & Number & Percent \\
\hline \multicolumn{3}{|l|}{ Sex } \\
\hline Male & 166 & 28.1 \\
\hline Female & 424 & 71.9 \\
\hline \multicolumn{3}{|l|}{ Age (in years) } \\
\hline$\leq 18$ & 23 & 3.9 \\
\hline $19-29$ & 418 & 70.8 \\
\hline $30-40$ & 114 & 19.3 \\
\hline$>40$ & 35 & 5.9 \\
\hline \multicolumn{3}{|l|}{ Marital Status } \\
\hline Single & 252 & 42.7 \\
\hline Married & 263 & 44.6 \\
\hline Widowed/divorced & 75 & 12.7 \\
\hline \multicolumn{3}{|l|}{ Educational status } \\
\hline Illiterate & 186 & 31.5 \\
\hline Primary education & 194 & 32.9 \\
\hline Secondary education & 153 & 25.9 \\
\hline Above secondary education & 57 & 9.7 \\
\hline \multicolumn{3}{|l|}{ Religion } \\
\hline Christian & 442 & 74.9 \\
\hline Muslim & 148 & 25.1 \\
\hline \multicolumn{3}{|l|}{ Monthly salary (in Birr) } \\
\hline$\leq 700$ & 285 & 48.3 \\
\hline $701-1500$ & 245 & 41.5 \\
\hline$>1500$ & 60 & 10.2 \\
\hline \multicolumn{3}{|l|}{ Work experiences (in years) } \\
\hline$<5$ & 416 & 70.5 \\
\hline$\geq 5$ & 174 & 29.5 \\
\hline
\end{tabular}


the employees had worked for $\leq 48 \mathrm{~h}$ per week. Twothirds, $66.8 \%$, of them worked overtime. About threefourths $(71.7 \%)$ were dissatisfied with their current job, and $62.7 \%$ were stressed. The majority, $89.3 \%$ and $85.4 \%$, of them had no pre-employment screening and periodic medical checkup, respectively. More than twothirds, $69.0 \%$, of them didn't receive attendance-based incentive (Table 2).

\section{Magnitude of sickness absenteeism}

The magnitude of sickness absenteeism among horticulture employees was observed to be $58.8 \%$ [95 \% CI: $(54.9,62.5)]$ in the past three months. Of whom $73.5 \%$ were females. The majority, $72.6 \%$ and $69.7 \%$, of them belonged to the age group of 19 to 29 years and attended primary and below education, respectively. The average frequency of absence was 1.73 [95 \% CI: $(1.63,1.84)]$. The mean number of lost working days per absentee was 6.63. The total of 2302 working days was lost.

Table 2 Workplace characteristics of horticulture employees in Lume district, southeast Ethiopia, 2014

\begin{tabular}{|c|c|c|}
\hline Variables & Number & Percent \\
\hline \multicolumn{3}{|c|}{ Employment type } \\
\hline Permanent & 526 & 89.2 \\
\hline Temporary & 64 & 10.8 \\
\hline \multicolumn{3}{|c|}{ Working hours per week } \\
\hline$\leq 48$ & 523 & 88.6 \\
\hline$>48$ & 67 & 11.4 \\
\hline \multicolumn{3}{|l|}{ Work overtime } \\
\hline Yes & 394 & 66.8 \\
\hline No & 196 & 33.2 \\
\hline \multicolumn{3}{|l|}{ Job satisfaction } \\
\hline Satisfied & 167 & 28.3 \\
\hline Dissatisfied & 423 & 71.7 \\
\hline \multicolumn{3}{|l|}{ Workplace stress } \\
\hline Not stressed & 220 & 37.3 \\
\hline Stressed & 370 & 62.7 \\
\hline \multicolumn{3}{|c|}{ Pre-employment medical } \\
\hline \multicolumn{3}{|l|}{ Screening } \\
\hline Yes & 63 & 10.7 \\
\hline No & 527 & 89.3 \\
\hline \multicolumn{3}{|c|}{ Periodic medical checkup } \\
\hline Yes & 86 & 14.6 \\
\hline No & 504 & 85.4 \\
\hline \multicolumn{3}{|c|}{ Received attendance-based incentive } \\
\hline Yes & 183 & 31.0 \\
\hline No & 407 & 69.0 \\
\hline
\end{tabular}

\section{Perceived causes of sick absenteeism}

The most common health problems that lead employees away from their work were $48.7 \%$ minor illness, $36.6 \%$ typhoid, 35.7 \% diarrhea, 32.3 \% Musculo-Skeletal Disorders (MSDs) (Fig. 1).

\section{Factors associated with sickness absenteeism}

Table 3 presents factors which remained statistically significant in the bivariate and multivariable logistic regression analyses. In this study, the independent predictors of sickness absenteeism on the multivariable analysis include absence of periodic medical checkup [AOR: 3.6, 95 \% CI: $(2.1,6.1)]$, working for $>48 \mathrm{~h}$ per week [AOR: 1.9, $95 \% \mathrm{CI}:(1.0,3.5)]$, working overtime [AOR: 2.8, $95 \% \mathrm{CI}:(1.9,4.2)$ ], job dissatisfaction [AOR: 1.8, $95 \% \mathrm{CI}:(1.2,2.7)]$, and job stress [AOR: 2.0, 95 \% CI: $(1.4,2.9)]$, (Table 3).

\section{Discussion}

Sickness absenteeism remains to be the major occupational health problem among horticulture employees. In this study the magnitude of sickness absenteeism among horticulture employees was $58.8 \%$ [95 \% CI: $(54.9,62.5)]$. This finding is higher than that of studies from Ethiopia (53.9\%) [15], Nigeria (15.8-25.0 \%) [16, 17] and Denmark (12.0\%) [18]. The difference could be due to methodological differences, like study population and methods of data collection, and workplace conditions, like employees' level of awareness on hazard control and disease prevention and accessibility to health care services [15-18].

This study identified important predictors influencing sickness absenteeism. Employees who didn't undergo periodic medical checkup were more likely to experience sickness absenteeism than those who did so. Timely medical examination helps as a preventive medicine for detecting and treating early initiation of health problems on regular basis before it goes to hard step. Thus, it is a moral imperative for the employers to know health status of their employees periodically and take the necessary interventions to protect them from further harming.

In this and other studies employees who worked for greater than $48 \mathrm{~h}$ per week were more likely to experience sickness absenteeism than those who did not $[5,19]$. This is true for employees who engaged in overtime work [20]. The reason could be that working above normal working hours would affect muscular activities and caused mental fatigue which might lead employees to increased risk of accidents. It could be recommended that assignment of employees should take into account the implementation of shiftwork scheduling. Moreover, recruiting additional employees could also improve the situation.

Job dissatisfaction and stress were also found significantly associated with sickness absenteeism. Other studies support these findings [21-24]. Existing research has 


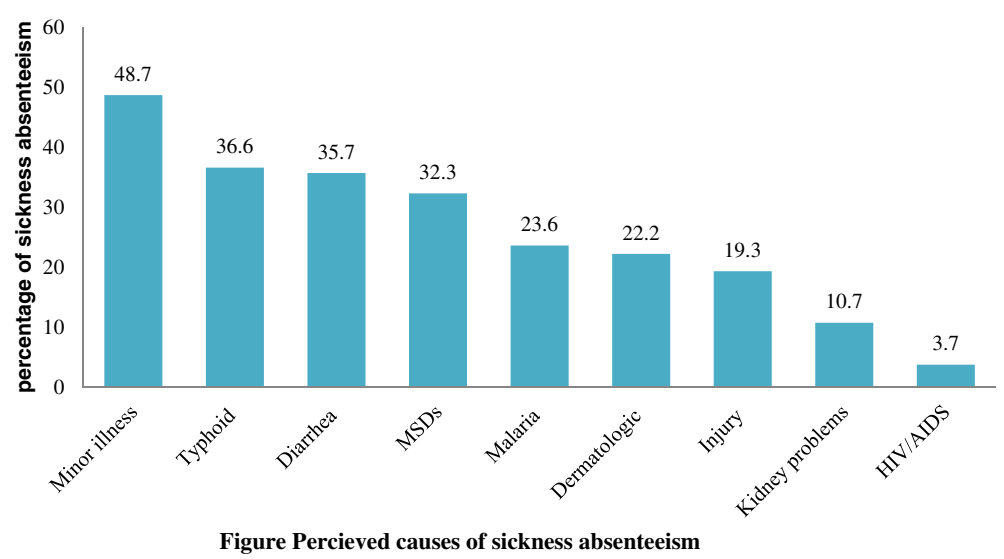

Fig. 1 Percieved causes of sickness absenteeism

recognized heavy workload, insufficient resources, work relationships, lack of professional respect, and lack of promotion opportunities as possibly the most salient job stressors [25-27]. Chronic exposure to stress may be harmful to the health of employees and may also affect productivity of organization through employee dissatisfaction, burnout, poor performance, high turnover, and increased absence from work [28-32].

Social desirability bias is a potential limitation in selfreported studies like this one, in that employees might report more socially acceptable responses than their actual day to day practice. As this is a cross-sectional study, the limitations that come with this type of design

Table 3 Factors associated with sickness absenteeism among horticulture employees in Lume District, southeast Ethiopia, 2014

\begin{tabular}{|c|c|c|c|c|}
\hline \multirow[t]{2}{*}{ Variables } & \multicolumn{2}{|c|}{$\begin{array}{l}\text { Sickness } \\
\text { absenteeism }\end{array}$} & \multirow[t]{2}{*}{$\begin{array}{l}\text { Crude OR } \\
(95 \% \mathrm{Cl})\end{array}$} & \multirow[t]{2}{*}{$\begin{array}{l}\text { Adjusted OR } \\
(95 \% \mathrm{Cl})\end{array}$} \\
\hline & Yes & No & & \\
\hline \multicolumn{5}{|c|}{ Periodic medical checkup } \\
\hline Yes & 36 & 50 & 1 & 1 \\
\hline No & 311 & 193 & $2.2(1.4,3.6)$ & $3.6(2.1,6.1)$ \\
\hline \multicolumn{5}{|c|}{ Working hours per week } \\
\hline$\leq 48$ & 302 & 221 & 1 & 1 \\
\hline$>48$ & 45 & 22 & $1.5(0.9,2.6)$ & $1.9(1.0,3.5)$ \\
\hline \multicolumn{5}{|l|}{ Worked overtime } \\
\hline No & 88 & 108 & 1 & 1 \\
\hline Yes & 259 & 135 & $2.4(1.7,3.3)$ & $2.8(1.9,4.2)$ \\
\hline \multicolumn{5}{|l|}{ Job satisfaction } \\
\hline Satisfied & 84 & 83 & 1 & 1 \\
\hline Dissatisfied & 263 & 160 & $1.6(1.1,2.3)$ & $1.8(1.2,2.7)$ \\
\hline \multicolumn{5}{|l|}{ Workplace stress } \\
\hline Not stressed & 106 & 114 & 1 & 1 \\
\hline Stressed & 241 & 129 & $2.0(1.4,2.8)$ & $2.0(1.4,2.9)$ \\
\hline
\end{tabular}

need to be taken into consideration when interpreting the findings.

\section{Conclusions}

In this study a relatively higher rate of sickness absenteeism was reported compared to other studies. Interventions to reduce sickness absenteeism should focus on areas, such as periodic medical checkup, monitoring work schedules, improving employees' job satisfaction, and reducing workplace stress.

\section{Competing interests}

The authors declare that they have no competing interest.

\section{Authors' contribution}

Author 1. ST: Involved in write up of the research proposal, the data analyses, and wrote the manuscript, Author 2. KE: Involved in write up of the research proposal, the data analyses, and manuscript writingt, Author 3. ZG: Involved in write up of the research proposal, the data analyses, and manuscript writing. All authors read and approved the final manuscript.

\section{Acknowledgments}

The authors wish to thank the Oromia Labor and Social Affairs Bureau for logistic and administrative support, and data collectors for their support in making this study possible. They also extend their deepest gratitude to the study participants.

\section{Author details}

'Institute of Public Health, The University of Gondar, Gondar, Ethiopia.

${ }^{2}$ Labour and social affairs, Oromia Regional State, Addis Ababa, Ethiopia.

Received: 20 December 2014 Accepted: 7 August 2015

Published online: 12 August 2015

\section{References}

1. Royal Australasian College of Physicians. Workplace Attendance and Absenteeism. Sydney: Australasian Faculty of Occupational Medicine; 1999.

2. Finnish Institute of Occupational Health. Social determinants of health and the workplace. African Newsletter on Occupational Health and Safety. 2013;23(3):3.

3. Melchior M, Niedhammer I, Berkman LF, Goldberg M. Do psychosocial work factors and social relations exert independent effects on sickness absence? A six year prospective study of the GAZEL cohort. J Epidemiol Community Health. 2003;57:285-93.

4. Essy C, Omorogbe V, Orji I, Oyovwe L. Self-reported absenteeism among hospital workers in benin city, nigeria. Ghana Med J. 2008;42:1. 
5. International Labour Organization. Decent Work in Agriculture. International Workers' Symposium on Decent Work in Agriculture; Geneva: Bureau for Workers' Activities; 2009.

6. International Labour Organization. LABORSTA database. Geneva: Statistics Do; 2008.

7. International Labour Organization. Occupational accident report by region. Geneva: International labour conference; 2008.

8. Ahmed A. Horticultural Marketing in Ethiopia. Addis Ababa University; Ethiopia. 2007

9. World Health Organization/International Labour Organization. Occupational Health and safety in Africa. Addis Ababa: Meeting report. 2010.

10. Central Statistical Authority. Population and Housing Census of Ethiopia: Results for Amhara Regional State. Addis Ababa, Ethiopia: Central Statistical Authority; 2007.

11. Lume District Labour and Social Affairs Office. Second quarter work report. Modjo: Ethiopia. 2014

12. The Marlin Company and the American Institute of Stress. The Workplace Stress Scale. Yonkers, NY. Accessed on: 02/05/2014, Available at: http:// www.executivestresscoach.com/JOBSTRESS.html.

13. Macdonald S, Maclntyre P. The generic job satisfaction scale: Scale development and its correlates. Employee Assistance Quarterly. 1997;13(2):1-16.

14. Ministry of Labour and Social Affairs. Labour proclamation No.377/2003. Ministry of Labour and Social Affairs, Addis Ababa, Ethiopia; 2003.

15. Tadesse T, Kumie A. Prevalence and factors affecting work-related injury among workers engaged in Small and Medium-Scale Industries in Gondar wereda, north Gondar zone, Amhara Regional State, Ethiopia. Ethiop J Health Dev. 2007;21(1):25-34.

16. Erinoso $A O$, Bamgboye E. Sickness absenteeism in a Nigerian polytechnic. Afr J Med Med Sci. 1988;17(1):57-61.

17. Bamgboye EA, Al A. Sickness absenteeism in a Nigerian teaching hospital. East Afr Med J. 1992;69(8):450.

18. Ballebye M. Nielsen HO. Oxford Research Institute: Factors influencing sickness absence; 2008.

19. Viswanathan $R$, Sridharan $P$, Thiyagarajan $S$. Absenteeism-a menace to indian BPO industry. SMART J of Business Mgt Studies. 2013;9(1):43-50.

20. Taylor P, Pocock S, Sergean R. Absenteeism of shift and day workers: a study of six types of shift system in 29 organizations. British J of Industrial Medicine. 2000;29(2):208-13.

21. Nakata A, Takahashi M, Irie M, Ray T, Swanson NG. Job satisfaction, common cold, and sickness absence among white-collar employees: a cross-sectional survey. Ind Health. 2011:49(1):116-21.

22. Estryn BM, Kaminski M. Rates of sickness absenteeism among employees of a modern hospital: the role of demographic and occupational factors. British J of Industrial Medicine. 1985;42(11):787-8.

23. Aaviksoo E, Baburin A, Kiivet RA. Risk factors for sickness absence among Estonian employees. Occup Med. 2013;63(2):156-9.

24. Beyamin MS, Azar K, Esmaiel R, Mohammad FK, Zolaykha A, Bagherian FE, et al. Prevalence and causes of medical absenteeism among staff (Case study at Mazandaran University of Medical Sciences: 2009-2010). Mater Sociomed. 2013;25(4):233-7.

25. Kim HJ. Work stress and job satisfaction of community mental health nurses in South Korea: a qualitative content analysis. J Korean Acad Psychiatr Ment Health Nurs. 2013;22:295-306

26. Johnson SJ, O'Connor EM, Jacobs S, Hassell K, Ashcroft DM. The relationships among work stress, strain and self-reported errors in UK community pharmacy. Res Social Adm Pharm. 2014;10(6):885-95.

27. Qu NQ, Zhou H, Fan LH. Analysis on work stress and occupational burnout among community health service staff in Harbin. Med Soc. 2013;26:87-9.

28. Chen XJ, Tan XR, Li LP. Health problem and occupational stress among Chinese doctors. Chin Med. 2013:4:1-6.

29. Nabirye RC, Brown KC, Pryor ER, Maples EH. Occupational stress, job satisfaction and job performance among hospital nurses in Kampala, Uganda. J Nurs Manage. 2011;19:760-8.

30. Voltmer E, Rosta J, Siegrist J, Aasland OG. Job stress and job satisfaction of physicians in private practice: comparison of German and Norwegian physicians. Int Arch Occ Env Health. 2012;85:819-28.

31. Saijo Y, Chiba S, Yoshioka E, Nakagi Y, Ito T, Sugioka Y, et al. Job stress and burnout among urban and rural hospital physicians in Japan. Aust J Rural Health. 2013:21:225-31.
32. Sun $Y$, Luo ZN, Fang PQ. Factors influencing the turnover intention of Chinese community health service workers based on the investigation results of five provinces. J Commun Health. 2013;38:1058-66.

\section{Submit your next manuscript to BioMed Central and take full advantage of:}

- Convenient online submission

- Thorough peer review

- No space constraints or color figure charges

- Immediate publication on acceptance

- Inclusion in PubMed, CAS, Scopus and Google Scholar

- Research which is freely available for redistribution 